I.A.A.R.C.

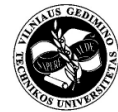

Institute of Internet and Intelligent Technologies

Vilnius Gediminas Technical University

Sauletekio al. 11, 10223 Vilnius, Lithuania

http://www.isarc2008.vgtu.lt/
The $25^{\text {th }}$ International Symposium on Automation and Robotics in Construction

June 26-29, 2008

ISARC-2008

\title{
DESIGN OF A HAPTIC DEVICE FOR EXCAVATOR EQUIPPED WITH CRUSHER
}

\author{
Kyeong Won Oh, Dongnam Kim \\ Korea University, Graduate School \\ 5Ga-1, Anam-Dong, Sungbuk-Gu, Seoul, Korea \\ \{locoski, smileast\}@korea.ac.kr
}

Jong-Hyup Park

Naekyung Engineeing Co., Ltd.

5-1 Sewon building, Yangjae-Dong,

Seocho-Gu, Seoul, Korea

nk2900@empal.com

\author{
Daehie Hong \\ Korea University, Division of Mech. Engineering \\ 5Ga-1, Anam-Dong, Sungbuk-Gu, Seoul, Korea \\ dhhong@korea.ac.kr
}

\section{Sukhie Hong}

Naekyung Engineeing Co., Ltd.

5-1 Sewon building, Yangjae-Dong,

Seocho-Gu, Seoul, Korea

hongcon@korea.com

\begin{abstract}
The dismantling processes are very dangerous and there have been many studies for utilizing a remote control system to increase operator's safety. This paper deals with the remote control problem by developing a novel haptic device to control an excavator equipped with the crusher which is one of the most frequently used attachments. Firstly, the newly designed haptic device is described to explore the operability to the excavator equipped with the crusher. Not only the excavator body but also its arm, boom, swing, and crusher are considered in the design. Then, its workspace is analyzed and the mapping between the haptic device and the excavator is examined. Also, the performance index of haptic device is used to discuss the control efficiency. Secondly, through the kinematics analysis about arm, boom, and swing motions of the excavator, the position information of each joint is analyzed in 3-dimensional space. Lastly, both the haptic device and the excavator are modeled using OpenGL program and 3D graphical simulations are extensively performed. The structure of this new haptic device is simple and can be easily manufactured. It can be used to operate the excavator with crusher more conveniently and transparently from a remote site away from the dangerous sites.
\end{abstract}

\section{KEYWORDS}

Haptic Device, Excavator, Crusher Attachment, Dismantling Process, Remote Control

\section{INTRODUCTION}

Today, there are lots of remodeling and dismantling of buildings to build new skyscrapers in construction sites. And to dismantle the building, excavator equipped with the crusher is the most frequently used. However, in this case, operators have to ride on the excavator directly, so they have had a lot of exposure to unexpected danger. 
There have been some current studies about the teleoperation of excavator to make up for its defects. First, remote control of excavator using Phantom, which is commercial haptic, was studied by Frankel [1]. And kinematics analysis and simulation of construction devices were conducted by Frimpong [2]. Moreover Hirabayashi [3] studied teleoperation of excavator, which was operated in underwater. And last, before this research, a new designed haptic device for excavator's motion is proposed by Kim [4].

In this paper, a novel concept of tele-operated haptic device is proposed, in order to make an offer more safe and efficient control to operator while in dismantling processes. This new haptic device is considered not only driving of excavator body but also controlling the basic motion of excavator such as swing, boom, arm and crusher. It has similarities to existing joystick of excavator and simple structure. So, operator can use haptic device easily, even if they control for the first time. To explain operation principle of the haptic device, first of all, kinematics analysis of excavator and haptic device has to be preceded through its modeling. And then, connection between excavator and haptic device should be discussed. Sometimes, it is impossible to control, because of exceedingly generation of reflection force. For more effective operation, it is important that operator takes cognizance of reflection force which is exerted on excavator especially crusher. So, a new designed haptic device is considered force feedback. Then, to increase performance and capability of haptic device, the performance index of haptic device should be analyzed. On this occasion, mapping is based on performance index, through analysis of workspace between excavator and haptic device. Lastly, both the haptic device and the excavator are modeled using OpenGL program and 3D graphical simulations are extensively performed.

\section{KINEMATICS OF EXCAVATOR EQUIPPED WITH CRUSHER}

\subsection{Modeling of Excavator}

In this paper, the excavator which has 4 basic motions, swing, boom, arm and bucket, among many kinds of backhoes is used. And this is equipped with crusher instead of bucket. Bucket joint has an only $1 \mathrm{DOF}$, rotation of bucket, originally. But, in this case, it has totally 5DOFs, because cutting and rotating motion are included in crusher. Hence, based on this motion, the coordinate system and motion of each link about modeled excavator equipped with crusher are shown in Fig. 1. There is one more DOF of rotational crusher joints about $X_{e 4}$ in large size of excavator, however it is not considered in this paper.

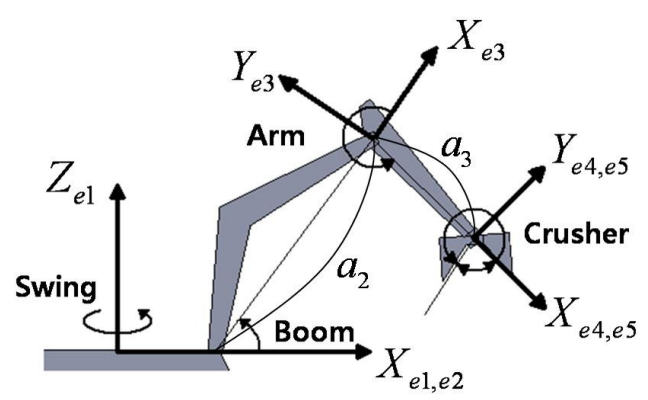

Figure 1. Modeling of Excavator Equipped with Crusher

Axis of swing joint is represented by $Z_{e l}$, and the rest of four joint axes, boom, arm, and crusher are also represented in sequence. Rotational axes of each link are perpendicular at Fig. 1 except for axis of swing.

\subsection{Kinematics Analysis of Excavator}

After this modeling process, forward and inverse kinematics analysis of excavator has to be studied. When the haptic devices are designed, especially, inverse kinematic is very important. When control motion of boom and arm are tried, these positions should be analyzed to understand whole of excavator status. Through, inverse kinematics analysis, the position of each link, boom, arm, and crusher can be acquired. In order to acquire information of position more easily for operator, position of crusher joint, arm's tip, is analyzed first of all [4]. In actuality, for dismantling processes, swing motion and motion of crusher do not take part in position of arm's distal joint. So, kinematics analysis can be treated 2dimentional problem of 2DOFs, boom and arm. This can be obtained by absolute position of the haptic stylus. Then, using this, the position of each link can be obtained by analysis of inverse kinematics. Following equations are inverse kinematics 
equations to calculate the angles of boom and arm.

$\theta_{e 2}=\tan ^{-1}\left(\frac{r_{24}(y)}{r_{24}(x)}\right)+\cos ^{-1}\left(\frac{a_{2}^{2}+r_{24}^{2}-a_{3}^{2}}{2 a_{2} r_{24}}\right)$

$\theta_{e 3}=\pi+\cos ^{-1}\left(\frac{a_{2}^{2}+a_{3}^{2}-r_{13}^{2}}{2 a_{2} a_{3}}\right)$

$\theta_{e i}:$ Rotational angle of excavator $(i=1,2,3,4)$

$r_{j k}$ : Distance between $Z_{e j}$ and $Z_{e k}(j, k=1,2,3,4)$

\section{THE NOVEL CONCEPT OF HAPTIC DEVICE}

\subsection{Design Concept and Kinematics}

A novel haptic device is similar to lever of excavator which is currently used. Fig. 2 shows new designed haptic device. Coordinate assignment is also shown in the figure with D-H coordinate system. The haptic device has 3 rotational joints, 1 prismatic joint, and buttons for crusher and a spherical joint for excavator driving. And the used parameter values are defined, as shown in Table 1. Motion of swing and crusher is directly connected to three joints of haptic device to provide convenience to operator. The swing motion is controlled by $\theta_{h 1}$ and motion of the crusher, rotation and nipping motion are controlled by $\theta_{h 4}$ and buttons, directly. And the position of arm's distal joint is controlled by only $\theta_{h 2}, d_{h 3}$ of haptic device and the angle of boom and arm can be calculated by analysis of inverse kinematics. It was pointed out in the previous chapter. And to calculate the position vector of endpoint of haptic stylus relative to base frame, transformation matrix $T$ is used like following equation (3). It is necessary that haptic device connect with excavator to control distal joint of arm.

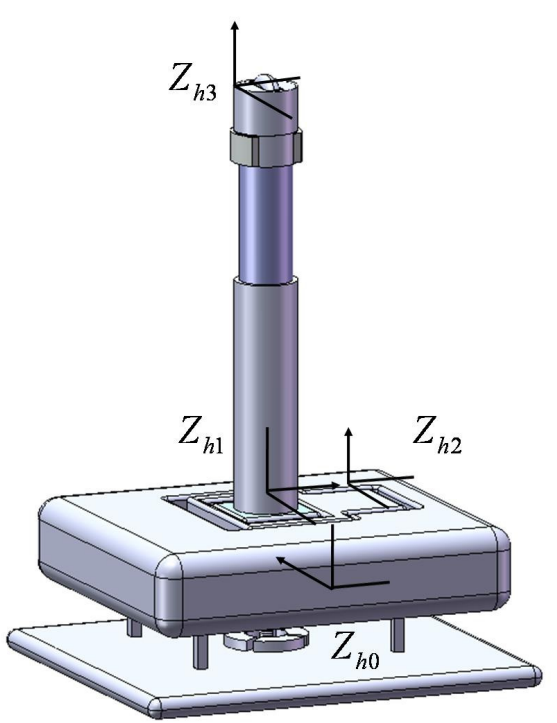

Figure 2. Haptic Device with D-H Coordinates

Table 1. D-H Parameters of Haptic Device

\begin{tabular}{|l|l|l|l|l|}
\hline Joint $i$ & $\theta_{h i}$ & $\alpha_{h i}$ & $a_{h i}$ & $d_{h i}$ \\
\hline 2 & $\pi / 2+\theta_{h 2}$ & $-\pi / 2$ & 0 & 0 \\
\hline 3 & 0 & 0 & 0 & $d_{h 3}$ \\
${ }^{i-1} T_{i}=\left[\begin{array}{cccc}\cos \theta_{i} & -\sin \theta_{i} \cos \alpha_{i} & \sin \theta_{i} \cos \alpha_{i} & a_{i} \cos \theta_{i} \\
\sin \theta_{i} & \cos \theta_{i} \cos \alpha_{i} & -\cos \theta_{i} \sin \alpha_{i} & a_{i} \sin \theta_{i} \\
0 & \sin \alpha_{i} & \cos \alpha_{i} & d_{i} \\
0 & 0 & 0 & 1\end{array}\right]$
\end{tabular}

And there are 5 actuators, electrical motors and 5 encoders inside the haptic device. The internal mechanism of haptic device appears in Fig. 3. The encoders read the angle of each link and the actuators offer force feedback to operator acting on excavator. In order to increase the efficiency of operation and the protection of equipment, it is necessary to detect the reflection forces. 


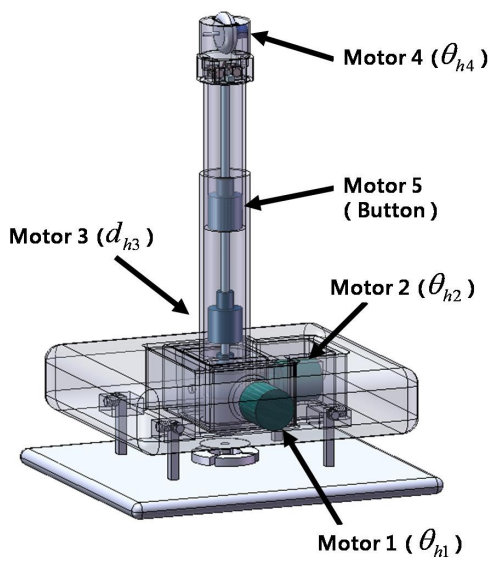

Figure 3. Internal Mechanism of Haptic Device

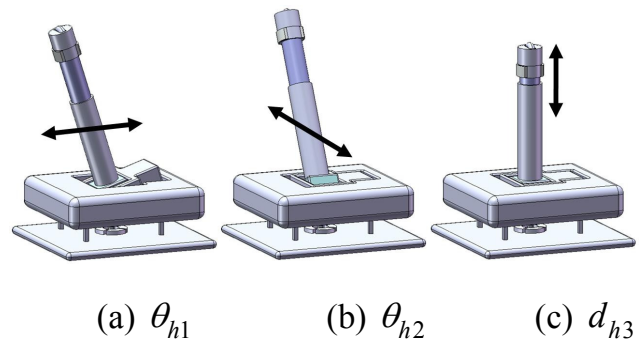

Figure 4. Motion of Haptic Device

\subsection{Motion of Haptic Device}

\subsubsection{Motion of Excavator}

Fig. 4 shows the motion of haptic device to operate $\theta_{h 1}, \theta_{h 2}$ and $d_{h 3}$. To provide simple functional adaptation, operation method of haptic device is designed quite similar to excavator. When an actual condition, the swing of excavator is controlled by the right and left movement of left side lever. And operation of boom and arm is controlled by front and rear motions of each side joystick. So, the swing motion is represented by right and left motion of haptic, $\theta_{h 1}$, just like excavator's controller. And operation is progressed in actual, operator usually control motion of boom and arm at the same time with both hands, through moving the lever front and rear. The haptic device is designed similarly. Using the haptic device, operator also can control boom and arm at once through the combination of $\theta_{h 2}$ with $d_{h 3}$. Fig. 4 (a) is a picture of $\theta_{h 1}$ and Fig. 4 (b), (c) show the motion of $\theta_{h 2}$ and $d_{h 3}$.

\subsubsection{Movement of Haptic Device for Crusher}

In order to operate more simply, shape and operating principle of crusher should be considered. Fig. 5 is an extended picture of crusher part of haptic. The nipping motion of crusher can be operated easily by fingers of operator. While pushing the buttons, operator makes fingers like tweezers and takes the motion similar to crusher. And rotational motion of crusher is operated by thumb wheel. The motions of crusher are controlled directly like swing.

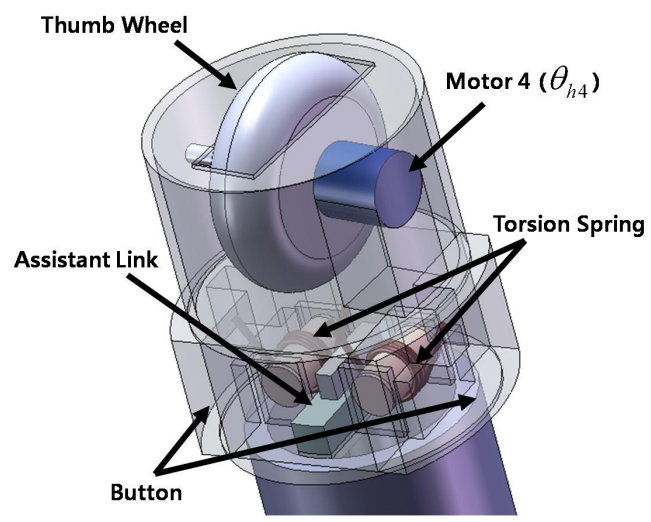

Figure 5. Crusher Part of Haptic Device

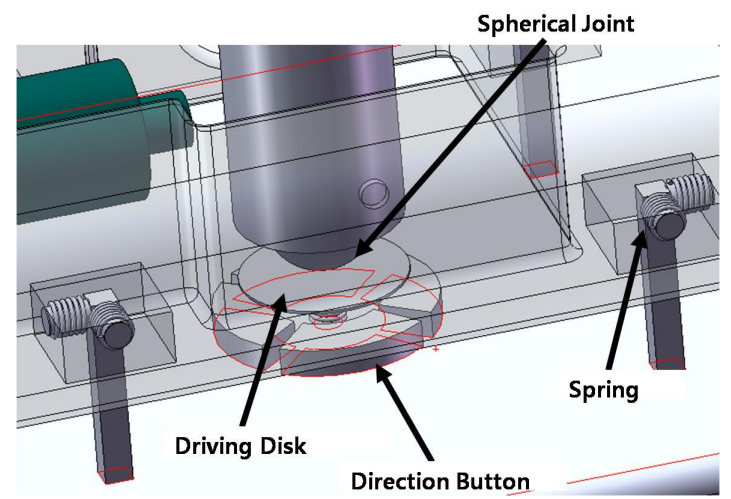

Figure. 6. Driving Control Part of Haptic Device

While the work is progressed, operator should have a grasp of the problem about reflection force acting on crusher to improve efficiency. For this reason, the inside of haptic device that has torsion springs, servo motor [5]. 
If the crusher takes a nipping motion without object, an assistant link which is connected with the servo motor can move up and down as torsion springs hold its shape. If the crusher dismantles some objects, torsion springs will be changed by the movement of assistant link. Owing to the servo motor pushes up the assistant link that depends on the action of reflection force upon the crusher. At this moment, operator can perceive the force that is exerted on crusher by increased moment of torsion spring. If there is an outbreak of great force over the limit, the servo motor will prevent the assistant link from moving and protect the crusher.

\subsubsection{Driving Control Using Haptic Device}

In this study, one of the notable features of the new designed haptic device is that operator can control each link of excavator and drive body using only one joystick, as shown in Fig. 6. For the driving excavator, first, the haptic stylus should be taken down. In this case, another part of haptic device holds the initial position of theirs so as not to operate during the driving. The bottom of stylus equipped with spherical joint so that it can move freely. And spherical joint pushes down the direction button. While the driving of excavator is controlled, the whole of upper body of haptic device will move to any direction relative to the base frame of haptic device. And equipped springs make the stylus move to initial position. There are force-sensors under the button, so that velocities of both caterpillars are controlled separately by the pressure.

\section{WORKSPACE MAPPING AND PERFORMANCE INDEX}

\subsection{Workspace Analysis of Excavator}

Workspace of excavator should be analyzed to evaluate the performance index of haptic device. Fig. 7 shows the workspace of excavator by boom and arm from the side view without swing motion. Parameters are based upon a small size excavator, SOLAR 015, which has 1.5 tons of receptive capacity. In the figure, rotational axis of boom is the origin. When the boom joint moves from -56 to 74 degrees, the cross points represent the trajectory points of distal joint of boom. And dot points represent joint of arm when the range angle of arm is from 218 to 328 degrees. For the reason mentioned previous chapter, end-point of arm, the position of crusher joint, is controlled ultimately. Now to conclude, this area can be defined as workspace of excavator.

\subsection{Workspace Mapping and Performance Index}

The distal joint of arm is controlled by end-point of haptic stylus. So, workspace of excavator should be covered by workspace of tip of stylus, completely. Fig. 8 shows workspace mapping between excavator and haptic device. Workspace of haptic device is concerned about only $\theta_{h 2}, d_{h 3}$, because end-point of stylus connected with distal joint of arm are the most needed. Although there is an angle difference in workspace analysis, which it is not concerned, operator can put to rights it by intuition during the dismantling process. And performance index is defined, as shown in equation (4). For the better performance index, $\theta_{h 2}, d_{h 3}$ and remaining area should be as small as possible on mapping.

$$
\text { P.I. }(A, D, R)=\frac{(1-R) \times 100}{A \times D}
$$

When the performance index is bigger, the more efficient operation can be advanced. In this equation, $A$ is the range of $\theta_{h 2}$, this value is from 50 to 90 degrees. And $D$ is the range of $d_{h 3}, R$ is the ratio of remaining area which is calculated by AutoCAD.

In this paper, among all plausible cases, three of them which have the best results were compared, and then, the best performance index is decided. Now, in order to adjust difference dimension between excavator and haptic, scaling factor is applied and same scaling factor is used, 30. The first case, the function is P.I. $(82,0.066,63.0)$ and the value of function is 11.64 . And the second case, P.I. $(60,0.070,55.5)$, the performance index is evaluated by 13.21 . And then, in the last case, P.I.(57, 0.071,59.5), 14.70 is performance index. At this moment, the most efficient operation will be progressed. As this result, workspace of haptic device can be defined. 


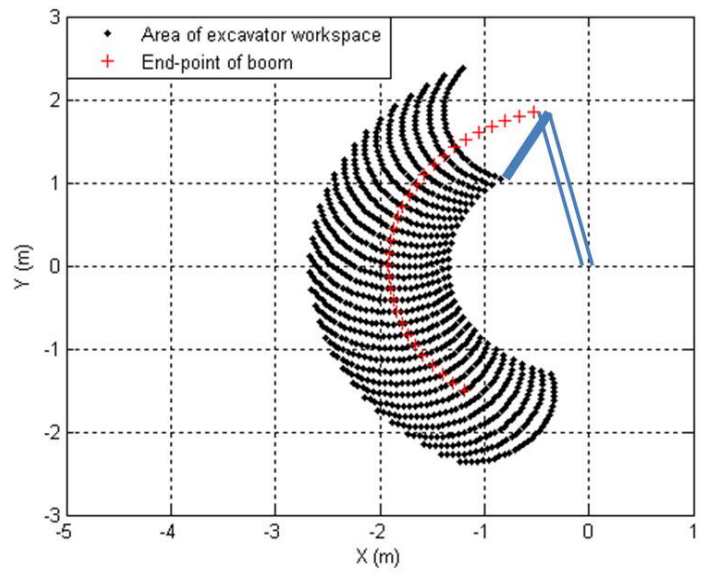

Figure 7. Workspace of Excavator

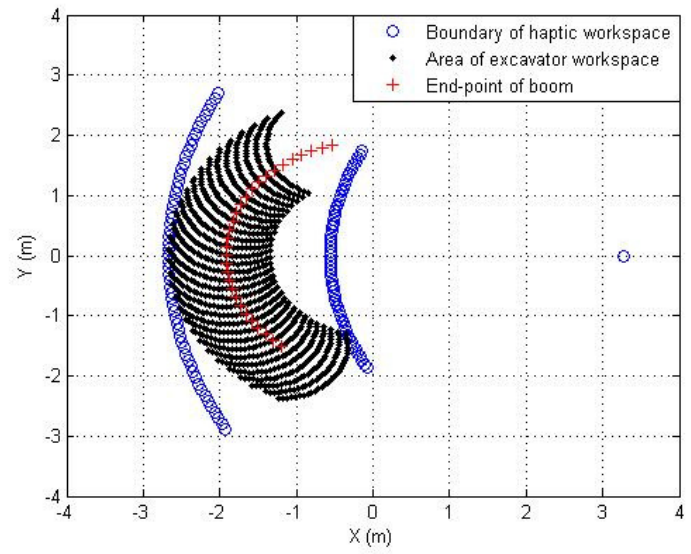

Figure 8. Workspace Mapping between Excavator and Haptic Device

Table 2. Simulation Results Using OpenGL Program

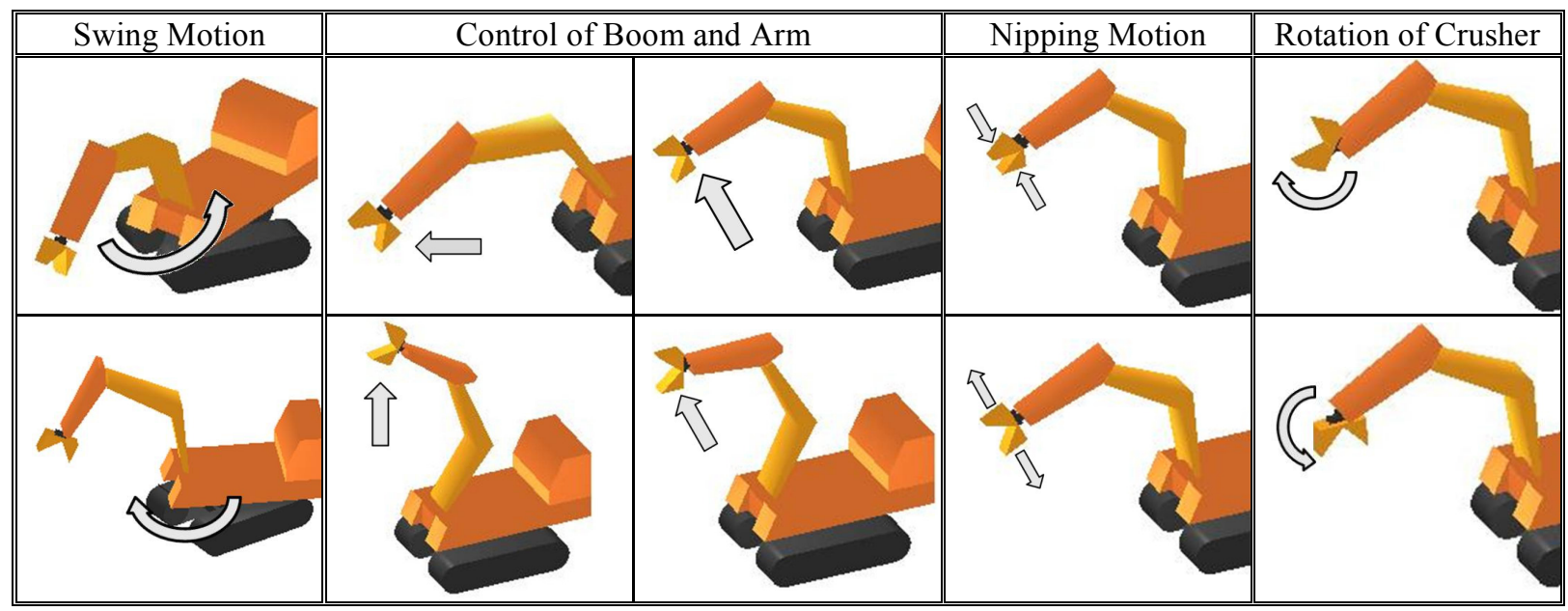

\section{SIMULATION RESULTS}

Table 2 summarizes simulation results which are modeling of excavator equipped with crusher using OpenGL program and movements of excavator are shown. One exception to this is driving motion, since it is not easy to display on figure.

In the simulation, this program works in real time. So mouse is used to control haptic and position of mouse cursor represents the $2 \mathrm{D}$ position of crusher joint, and thumb wheel is directly used to control rotation of crusher. Swing and driving of excavator is controlled by pushing the arrow key.

\section{CONCLUSION}

In this paper, the haptic device is newly designed to control excavator equipped with crusher. Kinematics and workspace analysis are conducted and performance index is evaluated by workspace mapping. Then, using OpenGL, graphical simulation 
control of excavator is included. As a result, intuitively convenient haptic device is designed.

\section{ACKNOWLEDGEMENTS}

This research was supported by a grant (code : 06 Construction Core B04) from Construction Core Technology Program funded by Ministry of Construction \& Transportation of Korean government and BK21.

\section{REFERENCES}

[1] Frimpong, S.; LI, Y. 2005, "Virtual prototype simulation of hydraulic shovel kinematics for spatial characterization in surface mining operations", International Journal of Surface Mining, Reclamation and Environment Vol. 19, No. 4, pp. 238 250.
[2] Frankel, J. G. 2004, "Development of a Haptic Backhoe Testbed", A Thesis of Master of Science, School of Mechanical Engineering Georgia Institute of Technology.

[3] Hirabayashi, T.; Yamamoto, T. 2006, "Experiment of Teleoperation of Underwater Backhoe with Haptic Information", $23^{\text {rd }}$ International Symposium on Automation and Robotics in Construction, pp. 36 41.

[4] Kim, D.; Hong, K.; Oh, D.; Park, J.; Hong, S. 2007, "Design of Haptic Device for Dismantling Process Using Excavator", 24 ${ }^{\text {th }}$ International Symposium on Automation \& Robotics in Construction, pp. 175 180.

[5] Oh, K.; Kim, D.; Hong, D.; Park, J. 2007, "Design of a Haptic Device for Crusher Attachment of Excavator", Korean Society for Precision Engineering 2007 Spring Conference, pp. 381 382. 